\title{
PLANNING OF INTERMEDIATE TRANSPORT SYSTEM FOR BENGALURU METROPOLITAN CITY TO COUNTER NOISE AND AIR POLLUTION
}

\author{
M R Raja Shekhara ${ }^{1}$, R. Madhusudhan ${ }^{2}$ \\ ${ }^{1}$ Professor and PG Coordinator, Civil Engineering Department, DSCE, Bengaluru-560 078 \\ ${ }^{2}$ Assistant Professor, Civil Engineering Department, Dr AIT, Bengaluru-560 056
}

\begin{abstract}
Intermediate transport system in any city plays a very important role in commuting people for a short distance, and ferries commuters in to the interior of the city thus providing timely service and in depth accessibility. This avoids long waiting time, easy availability on time. But the serious disadvantage is that excess number of such vehicles increases traffic congestion, noise and air pollution in addition to wastage of valuable fuel imported at huge foreign exchange. Proper and scientific planning and issuing permits prevents all the ill effects of excess number of auto rickshaws on the roads. This would relieve many problems the city is currently facing due to large number of such vehicles. This paper deals with a simple methodology of estimating the demand and supply of auto rickshaws and issuing permits only for representative number of vehicles as per the requirements.
\end{abstract}

\section{PRESENT SCENARIO OF BENGALURU CITY URBAN TRANSPORTATION}

Bengaluru city has spread across the four directions to an administrative area of $850 \mathrm{~km}^{2}$ and this is about $1250 \mathrm{~km}^{2}$ approximately on which living depends on the various services rendered by the city of different types. The approximate population of this city is about 10 million and about $20 \%$ of the adjoining areas of the city are also dependent on this city. The corresponding radius of this city is about 33 $\mathrm{km}$ and $40 \mathrm{~km}$. the city has a total vehicle population of around 50 lakhs and a large number of vehicles registered outside the city and also state are plying on the city roads. The city has about 31 lakhs of two wheelers and 1.3 lakhs auto rickshaws. Another conservative estimate indicates that the total number of auto-rickshaw in this city is about 1.5 lakhs. Around 30 lakhs of people are dependent on this service. The city transport is provided by BMTC-Bengaluru Metropolitan Transport service having a total fleet of about 6700 buses and around 45 lakhs passenger trips are supported by this mode. The per capita trips performed by the people is about 1.3 to 1.4 , which means that the total demand for city transport is about 16 millions. The various trips performed may be categorized as work, education, business, entertainment, religious, social, sports etc

The importance of the city has grown over period of two decades due to the high growth rate witnessed in the field of IT and BT field which offered lot number of jobs which are highly paid sectors. The result of this indicated the rise in the living standard of the people with high disposable income.
This increased the affordability level of people followed by tendency to go for own mode of transport. This increased vehicle population was witnessed only in two wheeler and car population. Presently the city has about 31 lakhs of two wheelers and about 7 lakhs of cars. Added to this the grossly inadequate public transport in the form of more walking distance and walking time before and after trips, more waiting time, inconvenience during travel, unreliability, costly fare etc the people are forced to switchover o personalized transport. The increased vehicle population is seen in auto rickshaw sector also.

Very high volume of vehicular flow on existing roads that are already constrained is resulting is drop in operating speeds of the vehicles and lowered level of service during peak and off peak hours. The increase in vehicle population and poor planning of the road network has resulted in increased increase in accident rate, the effect of which the numbers of causalities are around 1000 per year and number of injured persons are around 5,000 apart from huge loss of productive time, medication expenses, property damage, long court procedures, followed by awarding compensations towards compensation settlements. This does not include the family sufferings agony due to death, physical impairment of suffered for the rest of their life. 


\section{MEANING AND CONCEPT OF INTERMEDIATE TRANSPORT SYSTEM FOR}

\section{THE CITY}

City transport involves travel for different purposes, at different timings and for different distances which may not be possible by one mode of public transport. Also due to improper road network development in the interiors of the residential areas public transport buses could not be operated due to inadequate road width, turning radius. Lack of space for constructing bus stand or shelter also adds to the problems. Hence it may be necessary to depend on another mode of travel for short hauls. Normally this is met with by Intermediate Transport Service like auto rickshaws or taxis. These are suitable for short distance travel above $2 \mathrm{~km}$. Due to improper and inadequate planning of city transport, a large number of commuters are dependent on such modes and most of this is met with by unauthorized auto which exists all over the city. Normally these auto rickshaws ferry about 5 to 7 people at a time on fixed charges per person.

\section{PROPER PLANNING OF INTERMEDIATE TRANSPORT SYSTEM}

Intermediate Transport System is a next level transport system, where commuters use this transport system to reach the main transport system like bus transport, metro rail etc which are meant for long distance travel within the metropolitan city. Normally feeder services are better to support the main transport system, which improves the connectivity to a greater area. Hence there is need to establish the actual demand for ITS in the city. The major modes of transport in ITS is either auto rickshaw or taxi service. It may also be served by mini buses for short haul operations. This serves the commuters to reach the interior part of the city that provides better connectivity and thus avoid using personal transport. Depending on the travel characteristics of the commuters it may serve as main transport system also.

In spite of many advantages, it is very difficult to estimate the actual demand and supply for secondary or intermediate mode of transport system. The demand also fluctuates depending on hour of the day, weekdays, month etc. this makes it difficult to make an estimate of the actual demand for ITS. This data should be made available as a part of main or comprehensive traffic and transportation studies. The segregation of data for secondary mode could be easily done from this data.

\section{PRESENT SCENARIO OF ITS}

As mentioned earlier auto rickshaw and taxi forms the major secondary mode of transport system in this city. As per the statistics the total number of auto rickshaws in the city is in the range of $1,30,000$ to $1,50,000$ and more than 30,000 taxis are in operation. Of all the auto rickshaws only about 90,000 hold permits for operation. This is due to the fact that the demand for the transport is more than supply.

\section{METHODOLOGY FOR SCIENTIFIC PLANNING OF ITS}

The principle of this method of planning of ITS is based on actual data obtained from field study, estimating the demand for ITS and deciding the actual number of such vehicles required to satisfy the demand without permitting the excess of ITS vehicles. The method is more scientific and it is possible to achieve a balanced number of demands and supply of secondary mode of transport.

- Comprehensive data collection for the entire city based on the sample data for households, the travel demand from different zones to different zones based on assumed grid pattern

- Separation of primary and secondary travel pattern of travel thus identifying the actual demand for ITS

- Estimation of hourly variation in demand for secondary mode of travel by auto rickshaws

- Estimate the actual available auto rickshaws as ITS

- The difference between the supply and available provides the excess supply

- Measures to with draw excess vehicles

Another method of determination of actual number of vehicles is by cordon counts of vacant auto rickshaws plying in different parts of the city and this data may be collected during different hours of the day during different weekdays. This provides a proper plant form for deciding the excess vehicles. The actual number required should be worked out based on demand and supply principle. Appropriate steps should be taken to issue permits only to registered or authorized people.

\section{CORRECTIVE MEASURES}

As the corrective measures may have different implications, the methods should be carefully thought off and implemented. Else it may take to different problems and may lead to different problems in the city

- Convince the auto drivers to accept 8 hours duty per day and make shifts between 6 Am to 2.00 PM, evening shift between 2.00 to 10.00 $\mathrm{PM}$

- Issue separate permits for night operation between $10.00 \mathrm{PM}$ to $6.00 \mathrm{AM}$ as this constitutes only limited demand

- Issue all drivers with authorized permits with pass code for activation with server that houses all data 
- Each driver intending to work first enters the pass number with code and activates his account for the day either in the morning or afternoon

- For each trip the vehicle makes, the vehicle is guided with GPS for tracking the exact distance and destination, then it is charged as per actual distance moved

- This eliminates the unnecessary long hauls for new comers to the city

- Use IT for building the contact with commuters intending to travel by autos by SMS and the GPS guides the nearest auto to reach the commuter in shortest distance with the aid of GPS

- This facilitates easy availability of vehicles to commuters and also facilitates to continue their journey

- No wastage of time and money, billing as per actual

\section{CONCLUSIONS}

Proper planning of ITS is very essential to minimize the problems associated with excess number of vehicles, to counter loss of fuel and time, easy availability of vehicles to the commuters with better connectivity to all places of the city. This also relieves the city lot of traffic problems, pollution due to excess autos. A rough estimate indicates that about 1,20,000 autos are adequate to cater to the demand of the people from morning to evening of the day up to night. Stringent steps are necessary to curb the menace of excess of vehicles. 